\title{
Climate finance justice: International perspectives on climate policy, social justice, and capital
}

\section{Introduction}

In the 2015 Paris Agreement, the United Nations Framework Convention on Climate Change (UNFCCC) established, for the first time, the international community's intention to direct sufficient finance to address climate change. Along with the goals of "pursuing efforts to limit the temperature increase to $1.5^{\circ} \mathrm{C}$ above pre-industrial levels" and "increasing the ability to adapt to the adverse impacts of climate change," Article 2 of the Agreement recognized that "finance flows" were essential to achieve these longstanding goals of "low greenhouse gas emissions and climate-resilient development" (COP21 2015; Whitley et al. 2018). The UNFCCC's Standing Committee on Finance (SCF) takes a comprehensive view of climate finance, defining it as finance aimed at "reducing emissions, and enhancing sinks of greenhouse gases and... at reducing vulnerability of, and maintaining and increasing the resilience of, human and ecological systems to negative climate change impacts" (SCF 2014, 5). More specifically, climate finance typically consists of grants, loans, equity in the form of purchased shares, and debt relief. In the SCF's Biennial Assessment of climate finance flows, total global funding in 2016 was calculated to be USD 681 billion, as a high-bound estimate. This was an increase of $17 \%$ over the previous two years, with most of the growth occurring in new private investments in renewable energy projects (SCF 2018).

The politics of climate finance are centered on the recognition that the Global North has disproportionately benefited from fossil fuel production and use, while the Global South experiences more severe hazard events, such as droughts and storms, with higher levels of vulnerability to them. According to this framing, the Global North has both the moral responsibility to fund climate change mitigation and adaptation responses and the greater capacity to do so. Climate finance is thus a reaction to historical and ongoing injustice at the same time that it needs to be interpreted through the framework of justice. In this special issue, we explore the multiple and contested intersections of climate justice and finance. What kinds of justice and injustice do we see in climate finance? And how does climate justice influence flows and constructions of capital?

Guest Editors: Dr. Lauren Gifford (University of Colorado, Boulder) and Dr. Chris Knudson (University of Hawai'i at Hilo) 
The financial responsibility of the Global North was codified in the UNFCCC's 2010 Cancún Agreements: “...developed country Parties commit, in the context of meaningful mitigation actions and transparency on implementation, to a goal of mobilizing jointly USD 100 billion per year by 2020 to address the needs of developing countries" (COP16 2010). The Paris Agreement extended this commitment through 2025. In order to assess the progress in meeting this target, it is necessary to have internationally agreed upon rules for counting what qualifies as climate finance. However, these rules do not exist (Roberts and Weikmans 2017). Despite the resulting ambiguity, the two leading organizations that track climate finance have produced similar estimates of Global North financing. The aforementioned 2018 Biennial Assessment conducted by the SCF found that USD 55.7 billion flowed to the Global South in 2016, a 30\% increase over 2014 levels (SCF 2018). Similarly, the Organization for Economic Cooperation and Development produced a climate-related development finance database that recorded USD 56.7 billion of Global North funding in 2017 (OECD n.d.). When we compare the estimate of USD 681 billion for the entirety of climate finance in 2016, we see that Global North funding under the Cancún pledge accounts for less than $10 \%$. The majority of climate finance remains in the Global North to fund for-profit projects like renewable energy development (Yeo 2019).

The Paris Agreement establishes that there should be a balance in funding between adaptation and mitigation. However, approximately twice the amount of finance goes towards projects that are mitigation-only compared to adaptation-only (OECD n.d.). This has consequences for the mode of climate financing because most mitigation funding comes in the form of debt financing that needs to be paid back, while most adaptation funding consists of grants (SCF 2018). Moreover, the amount of global funding that does go towards mitigation and adaptation is grossly insufficient. The IPCC's Special Report on Global Warming of $1.5^{\circ} \mathrm{C}$ found that approximately USD 830 billion in "additional annual average energy-related investments" would need to be made between 2016 and 2050 to limit warming to $1.5^{\circ} \mathrm{C}$ by 2100 (Masson-Delmotte et al. 2018, sec. C.2.6). Adaptation costs are estimated to range between USD 70 and 100 billion annually, according to the IPCC's 5th Assessment Report (Chambwera et al. 2014). A more recent study by the United Nations Environment Programme found that annual adaptation costs in the Global South could increase to between USD 280 and 500 billion by 2050 (Puig et al. 2016).

\section{Emergent themes in climate finance justice}

Building from the movements against environmental racism and for environmental justice, climate justice as a distinct concept began to coalesce in the 1990s. A key moment was a meeting in Bali in preparation for the second Earth Summit, held in Johannesburg in 2002. The Bali Principles of Climate Justice were articulated by a coalition of groups, including CorpWatch, World Rainforest Movement, Friends of the Earth International, and the Indigenous Environmental Network. The 27 Bali Principles called for the elimination of greenhouse gases, "the rights of indigenous peoples and affected communities to represent and speak for themselves," and the "recognition of a principle of ecological debt that industrialized governments and transnational corporations owe the rest of the world," among other tenets common to the climate justice movement today (CorpWatch 2002). At COP13 (that is, the UNFCCC's $13^{\text {th }}$ conference of the parties) in Bali in 2007, representatives from the Global South and lowincome communities in the North united under the name "Climate Justice Now!". The group 
issued a series of "genuine solutions" that echoed many of the Bali Principles, but also significantly called for "huge financial transfers from North to South, based on the repayment of climate debts and subject to democratic control" (Tokar 2019).

We can identify two major theoretically divergent approaches to climate justice. First, there are thinkers based in philosophy and environmental ethics (Jamieson 2010a, b and Shue 1995) who frame climate change as a result of historic and current carbon emissions. They are concerned with who is responsible for existing carbon emissions, how future emissions should be quantified and valued, and who pays for climate impacts, and why. Second, there are those who approach justice from the perspective of social movements, interrogating the role of marginalization in the experience and suffering of climate impacts (Roberts and Parks 2006; Bond 2012). They address how social movements have united and gained traction under the umbrella of global climate concerns to challenge existing social and environmental injustices.

Climate justice-based arguments for climate finance typically draw on the twin principles of historical responsibility for climate change and of the greater capacity to act (Sayegh 2019). As part of the neoliberal turn toward environmental management, the Global North's increasing use of climate finance has included a reliance on markets and economic modelling, such as carbon taxes (Bumpus 2015), insurance (Johnson 2013), carbon offsets (Bumpus and Liverman 2008), payments for ecosystem services (McAfee and Shapiro 2010), cap and trade (Klinsky 2013), adaptation funds (Grasso 2009), and loss and damage compensation (Roberts and Huq 2015). But does this deployment of finance undermine other climate justice goals? What are the limits of using finance to pursue justice?

The articles in this special issue highlight several cross-cutting themes, including the reproduction of uneven development, the ongoing influence of increasingly weak institutions like the UNFCCC and the Green Climate Fund (GCF), the continued reliance on problematic financial mechanisms to address climate change, like trust funds, carbon offsets, the Clean Development Mechanism, and REDD+, and the problems that arise when local oversight and expertise are devalued or excluded. Other authors found that there is a common reliance on financial mechanisms to do development work; that universal finance tools can be ill-suited to accomplishing climate justice rooted in a particular place; and that many of these financial tools are complex by design, making accountability to, and interest in, climate justice difficult.

Our aim in organizing this collection of articles is to highlight recurring themes in critical research that demonstrate tensions between concepts of justice and economic models, financial tools, and flows of capital. These themes include the role of finance mechanisms like carbon markets, carbon offsets, and the GCF in raising and disbursing development aid; the ways that civil society is challenging how and by whom climate finance is administered; how social movements are pushing for capital flows to be managed by grassroots organizations rather than supranational institutions like the World Bank (Lohmann 2008); and ultimately how the complexities of finance and bureaucracy often obfuscate injustice.

\section{The articles in this special issue}

The articles in this special issue cover a broad international survey of climate finance justice. They range from richly empirical studies grounded in particular projects and places to critical analyses of the implications of using finance to manage climate change and redress its attendant losses. We begin with Khan et al.'s review of climate adaptation finance under the UNFCCC, from the early years of the COP process, through the middle Copenhagen era, to 
our post-Paris Agreement age. Drawing on multiple forms of justice - distributive, procedural, recognition, compensatory, restitutive, corrective, and neoliberal - the authors examine how adaptation finance has been variously understood and contested over time as new norms and rules arise. In analyzing whether the governance and delivery of adaptation finance has become more just, they focus on the questions of how much finance should be allocated, and by whom. While noting the ongoing reluctance of wealthy countries to accept responsibility for the climate catastrophe, the authors show how those in power continue to control policy development, which has led to justice commitments with little promise of ever being honored.

In the Paris Agreement, loss and damage (L\&D) joined mitigation and adaptation as the three fundamental pillars of climate change management. (L\&D is an umbrella term that encompasses the social, political, economic, or cultural impacts that lie beyond our capacity to adapt to climate change.) Williams addresses the convergence of scientific, legal, and policy communities in dealing with the direct and indirect impacts of anthropogenic climate change. Namely, she focuses on the development of the research field of scientific attribution, lawsuits against fossil fuel companies, and UNFCCC negotiations for L\&D. Within these three converging communities, Williams examines key conceptual and ethical issues concerning which communities become part of attribution studies and lawsuits, and which fossil fuel emitters are targeted by policy and the law. In doing so, Williams operationalizes an accountability-based approach to anthropogenic climate change by drawing on concepts of climate justice. She argues that an accountability-based approach should focus on those communities most impacted by climate change, in contrast to their relative neglect in detection and attribution work and in lawsuits. In addition, an accountability-based approach would also focus on the responsible agents, who can be identified by their significant contributions to emissions in combination with some improper act, such as negligence, the active avoidance of safer alternatives or blocking mitigation efforts.

In another policy-focused piece, Gifford examines the development and consequence of climate change mitigation products through an empirical focus on forest carbon offsets. By identifying three key 'points of engagement' in the carbon accounting process - baseline scenarios, additionality, and uncertainty - Gifford illustrates how activities deemed technical or apolitical are often spaces where uneven social and political interests are manipulated or obscured, leading to variable impacts in carbon sequestration and climate change mitigation. The article includes a review of the emergence of forest carbon offsets and how they evolved as objects of analysis in the social sciences, with a look at how accusations of carbon colonialism and fraud have led the mechanism to be reinvented in North/North contexts in the US. Conclusions are drawn from five years of field work, encompassing 77 interviews on forest carbon offsets in the Peruvian Amazon and in Maine, at the UNFCCC, at professional carbon market association meetings, civil society actions, and via participant observation in carbon accounting training courses.

Sauls shares another perspective on the use of conservation for climate change mitigation, as she questions how international climate finance can be used to protect forests in a way that accords with the affected communities' own conceptions of justice. For a coalition of ten Indigenous and forest peoples' groups in Mexico and Central America - the Mesoamerican Alliance of Peoples and Forests (AMPB) - one way to bring about more effective outcomes for mitigating climate change would be a variation on REDD+ that recognizes their territorial rights. While REDD+ funding typically relies on exogenous technical knowledge to calculate forest stocks and loss, the AMPB's proposal of a Mesoamerican Territorial Fund (MTF) as an 
alternative climate change finance mechanism is designed to accomplish both climate benefits and strengthen AMPB members' efforts for self-determination and support the survival of their cultural identities. However, there is a tension between the requirements that major donors place on entities to be fundable - for example, the need for performance-focused results - and the AMPB members' demands for autonomy and equity. Ultimately, Sauls sees an opening for climate finance like the proposed MTF to accomplish distributive, procedural, and historical justice on the territorial scale.

Shumais and Mohamed similarly explore another type of climate finance deployed within least developed countries: Environmental Trust Funds (ETFs). Their article examines the characteristics that make ETFs successful, with a particular emphasis on the relatively overlooked experiences of Small Island Developing States. An ETF is a government-led investment vehicle that can raise and distribute financial resources to address environmental issues. The authors focus on the Maldives's Climate Change Trust Fund (CCTF), which was set up in 2012 to enhance renewable energy, wetland management, coral reef monitoring and rainwater harvesting. Using the CCTF as a case study, the authors show that insufficient local expertise in renewable energy was a principal hindrance to the fund's success. The authors also compare the Maldives's CCTF with an ETF in Bhutan. They conclude that Bhutan's use of an autonomous and politically independent organization to facilitate its fund's projects led to greater success than in the Maldives where projects were directly managed by the ETF. Additional criteria for successful ETFs identified by the authors include stakeholder participation and the incorporation of objectives beyond those of the fund itself.

Cholibois explores another effort to expand renewable energy in the Global South, with a focus on the role that climate finance could have in Madagascar's energy transition. If Madagascar can receive sufficient funding, the construction of large-scale renewable energy - in a country largely lacking a national grid - would allow it to bypass the conventional path of fossil fuel consumption. Cholibois argues that climate finance is necessary for countries that struggle to fund development projects, such as Madagascar, whose per capita GDP was lower in 2010 than fifty years earlier. Madagascar has received climate finance in the form of grants and loans. Grantsbased electrification projects typically invest in complementary services, such as educational campaigns, and recognize the importance of bringing electricity to rural areas. However, the use of private capital, like concessional loans, is increasingly common in Madagascar, which risks excluding the poorest parts of rural Madagascar from the benefit of expanded electrification. This would undermine energy justice in the country by increasing inequality in access to electricity.

Finally, using the Lower Sesan 2 hydropower dam in Cambodia as a lens through which to consider flaws in the UN Clean Development Mechanism (CDM), Baird and Green demonstrate that hydroelectricity's promise of lowered greenhouse gas (GHG) emissions typically comes at the expense of other serious negative social and environmental consequences. The Lower Sesan, and other CDM-funded hydropower projects in Cambodia, have flooded forested areas, forced the relocation of communities, and blocked the migration of fish species. Moreover, there is often little proof that Cambodia's hydropower projects needed CDM financing to be built. This fraud has undermined mitigation efforts and taken funding from projects that could have resulted in additional cuts to GHG. As the CDM is scheduled to end in 2020 , there is the opportunity for its successor financing mechanism to rigorously uphold both clearly specified sustainable development goals and quantified reductions in carbon emissions.

A robust international movement has been organizing and advocating for climate justice for more than 10 years. And it has accomplished much. The Global North pledge at COP16 in Cancún to finance mitigation and adaptation was partly a response to the climate justice demands 
that asked wealthy countries to recognize their disproportionate responsibility for climate change and their capacity to act. Thus, because climate finance has been fundamentally framed as an issue of climate justice, we need to rigorously and comprehensively analyze the climate justice outcomes of these financial flows. We can state that the inability of the Global North to transfer USD 100 billion per year to the Global South, which is already insufficient for current needs, is in itself a failure of justice. As for how climate finance is being deployed, the articles in this special issue make clear that frequently the "winners" of financialized climate governance are neoliberal institutions, and other entities promoting market-based strategies for climate mitigation and adaptation. Ultimately, much of this research shows that justice remains more of a discursive tool than an action, with just climate finance still seemingly out of reach.

\section{References}

Bond P (2012) Emissions Trading, New Enclosures and Eco-Social Contestation. Antipode 44(3):684-701

Bumpus AG (2015) Firm Responses to a Carbon Price: Corporate Decision Making under British Columbia's Carbon Tax. Climate Policy 15(4):475-493

Bumpus AG, Liverman DM (2008) Accumulation by Decarbonization and the Governance of Carbon Offsets. Economic Geography 84(2):127-155

Chambwera M, Heal G, Dubeux C, Hallegatte S, Leclerc L, Markandya A, McCarl BA, Mechler R, Neumann JE (2014) Economics of Adaptation. In: Climate Change 2014: Impacts, Adaptation, and Vulnerability. Part A: Global and Sectoral Aspects. Contribution of Working Group II to the Fifth Assessment Report of the Intergovernmental Panel on Climate Change. Cambridge University Press, Cambridge, United Kingdom and New York, NY, USA, pp 945-977

COP16. 2010. "COP 16 Cancún Agreements."

COP21. 2015. "COP 21 Paris Agreement."

CorpWatch. 2002. "Bali Principles of Climate Justice.” 2002. https://corpwatch.org/article/bali-principlesclimate-justice.

Grasso, Marco. 2009. Justice in Funding Adaptation under the International Climate Change Regime. Springer Science \& Business Media.

Jamieson D (2010a) Climate Change, Responsibility, and Justice. Science and Engineering Ethics 16(3):431445

Jamieson D (2010b) Adaptation, Mitigation, and Justice. Climate Ethics, Essential Readings, pp 263-283

Johnson L (2013) Index Insurance and the Articulation of Risk-Bearing Subjects. Environment and Planning A 45:2663-2681

Klinsky S (2013) Bottom-up Policy Lessons Emerging from the Western Climate Initiative's Development Challenges. Climate Policy 13(2):143-169

Lohmann L (2008) Carbon Trading, Climate Justice and the Production of Ignorance: Ten Examples. Development 51(3):359-365

Masson-Delmotte, Valérie, Panmao Zhai, Hans-Otto Pörtner, Debra Roberts, Jim Skea, Priyadarshi R. Shukla, Anna Pirani, W. Moufouma-Okia, C. Péan, and R. Pidcock. 2018. "IPCC, 2018: Summary for Policymakers." In Global Warming of $1.5^{\circ}$ C. An IPCC Special Report on the Impacts of Global Warming of $1.5^{\circ} \mathrm{C}$ above Pre-Industrial Levels and Related Global Greenhouse Gas Emission Pathways, in the Context of Strengthening the Global Response to the Threat of Climate Change, Sustainable Development, and Efforts to Eradicate Poverty. Geneva, Switzerland: World Meteorological Organization.

McAfee K, Shapiro EN (2010) Payments for Ecosystem Services in Mexico: Nature, Neoliberalism, Social Movements, and the State. Annals of the Association of American Geographers 100(3):579-599

OECD. n.d. "Climate Change: OECD DAC External Development Finance Statistics." . https://www.oecd. org/dac/financing-sustainable-development/development-finance-topics/climate-change.htm.

Puig, Daniel, Anne Olhoff, Skylar Bee, Barney Dickson, and Keith Alverson. 2016. "The Adaptation Finance Gap Report." United Nations Environment Programme.

Roberts E, Huq S (2015) Coming Full Circle: The History of Loss and Damage under the UNFCCC. International Journal of Global Warming 8(2):141-157

Roberts JT, Parks B (2006) A Climate of Injustice: Global Inequality, North-South Politics, and Climate Policy. MIT press 
Roberts JT, Weikmans R (2017) Postface: Fragmentation, Failing Trust and Enduring Tensions over What Counts as Climate Finance. International Environmental Agreements: Politics, Law and Economics 17(1): 129-137 https://doi.org/10.1007/s10784-016-9347-4

Sayegh AG (2019) Climate Finance: Moral Theory and Political Practice. In: Tahseen J, Helwig K, Mikulewicz M (eds) Routledge Handbook of Climate Justice. Routledge, New York, NY, USA, pp 153-164

SCF. 2014. "UNFCCC Standing Committee on Finance: 2014 Biennial Assessment and Overview of Climate Finance Flows Report." UNFCCC Bonn.

SCF. 2018. "Summary and Recommendations by the Standing Committee on Finance on the 2018 Biennial Assessment and Overview of Climate Finance Flows." UNFCCC Bonn.

Shue H (1995) Equity in an International Agreement on Climate Change. Equity and Social Considerations Related to Climate Change. ICIPE Science Press, Nairobi

Tokar B (2019) On the Evolution and Continuing Development of the Climate Justice Movement. In: Tahseen J, Helwig K, Mikulewicz M (eds) Routledge Handbook of Climate Justice. Routledge, New York, NY, USA, pp $13-25$

Whitley S, Thwaites J, Wright H, Ott C (2018) Making Finance Consistent with Climate Goals: Insights for Operationalising Article 2.1c of the UNFCCC Paris Agreement. Overseas Development Institute, London

Yeo S (2019) Where Climate Cash Is Flowing and Why It's Not Enough. Nature 573(7774):328-331 https://doi. org/10.1038/d41586-019-02712-3

Publisher's note Springer Nature remains neutral with regard to jurisdictional claims in published maps and institutional affiliations. 